\title{
ESTUDO DAS PERDAS AUDITIVAS PROGRESSIVA E/OU DE APARECIMENTO TARDIO EM LACTENTES COM INDICADORES DE RISCO.
}

\section{Daniele Stradioto Ortolan*, Maria Francisca Colella dos Santos Curso de Fonoaudiologia-DDHR/FCM-Unicamp}

\section{Resumo}

A perda auditiva é uma alteração congênita muito comum em recém-nascidos e os primeiros anos de vida são críticos para a maturação auditiva. Considerando a importância de um diagnóstico precoce é imprescindível acompanhar periodicamente lactentes que passaram na triagem auditiva, mas apresentaram indicadores de risco para perda auditiva progressiva e/ou de aparecimento tardio em seu histórico neonatal.

\section{Palavras-chave:}

Indicador de Risco, Lactentes, Perda Auditiva.

\section{Introdução}

Os primeiros anos de vida são essenciais para a maturação e o desenvolvimento das habilidades auditivas. Objetivando o diagnóstico precoce, além da triagem auditiva neonatal, também é importante monitorar os lactentes, que passaram na triagem auditiva e apresentaram indicadores de risco para perda auditiva de aparecimento tardio e/ou progressivo ou para alterações no processamento auditivo, nos primeiros aos de vida ${ }^{2}$. $O$ monitoramento realiza avaliações periódicas até os dois anos e para cada faixa etária diferentes procedimentos são realizados para avaliar cada uma das crianças de acordo com o que é esperado para a idade ${ }^{4,5}$. O objetivo do presente trabalho foi analisar o desenvolvimento auditivo no primeiro ano de vida de lactentes que estiveram internados na UTI do CAISM/FCM/UNICAMP e que passaram na triagem auditiva neonatal, mas apresentaram indicadores de risco para perda auditiva ${ }^{3}$.

\section{Resultados e Discussão}

Esse projeto teve aprovação do Comitê de Ética em Pesquisa/FCM/UNICAMP sob protocolo de número 932.602/2015. A amostra foi composta por lactentes em seu primeiro ano de vida, do sexo masculino e feminino, que passaram pelo monitoramento auditivo realizado no CEPRE/Unicamp, de agosto de 2017 a abril de 2018. Os lactentes foram agrupados em dois grupos considerando a idade corrigida. O grupo 1 (6-9 meses) com 74 sujeitos e grupo 2 (9-13) com 58 sujeitos. A avaliação foi composta pelos seguintes testes: resposta comportamental para estímulos instrumentais, audiometria com reforço visual (VRA), resposta a voz familiar e/ou do examinador e imitanciometria. No grupo 1, para a localização sonora para cima e para baixo, $40 \%(n=30)$ dos lactentes não localizou a fonte nestas direções. No grupo 2, 50\% (n=29) dos lactentes avaliados realizaram localização indireta para baixo e para cima.

Tabela 1 - Lactentes dos grupos 1 e 2, segundo a resposta de localização sonora para baixo e para cima

\begin{tabular}{ccc}
$\begin{array}{c}\text { Localização } \\
\text { Para baixo/Para } \\
\text { cima }\end{array}$ & $\begin{array}{c}\text { Grupo 1 } \\
(6-9 \text { meses) }\end{array}$ & $\begin{array}{c}\text { Grupo2 } \\
(\mathbf{9 - 1 2} \text { meses) }\end{array}$ \\
\hline Indireto/indireto & $39(53 \%)$ & $29(50 \%)$ \\
\hline Direto/indireto & $05(7 \%)$ & $15(26 \%)$ \\
\hline $\begin{array}{c}\text { Direto/direto } \\
\text { Não localizou a } \\
\text { fonte }\end{array}$ & $0(0 \%)$ & $14(24 \%)$ \\
\hline
\end{tabular}

Estas respostas demonstram atraso no desenvolvimento da habilidade de localização sonora, já que espera-se localização lateral a partir dos $4 / 5$ meses e localização direta para baixo, aos 9 meses ${ }^{1}$. Nestes casos houve orientação aos pais e/ou cuidadores para estimular a audição das crianças. Para a avaliação de resposta a voz familiar e/ou do examinador encontrou-se os seguintes resultados: grupo $1,15 \%(n=11)$ e no grupo $2,5 \%(n=3)$, não localizaram ou apresentaram reação ao som, indicando um possível atraso nas habilidades de detecção e/ou reconhecimento de sons verbais ${ }^{1}$. Os lactentes também foram avaliados através da imitanciometria e da audiometria com reforço visual (VRA). Na imitanciometria, $14 \%(n=5)$ das crianças do grupo 1 e $27 \%(n=9)$ do grupo 2 apresentaram resultados alterados na imitanciometria, ou seja, curva timpanometria tipo B ou C. Não foi possível realizar a imitanciometria em todas as crianças. Os resultados obtidos na imitanciometria e VRA revelam alteração na transmissão do som pelo sistema tímpanoossicular. Nestes casos a conduta foi encaminhamento para avaliação e conduta pediátrica.

\section{Conclusões}

A partir da análise dos resultados obtidos verificou-se atraso no desenvolvimento das habilidades auditivas em $50 \%$ dos lactentes no primeiro ano de vida, além de alteração de orelha média em $27 \%$. O monitoramento auditivo é fundamental para a identificação precoce e estabelecimento de condutas adequadas.

\section{Agradecimentos}

Instituição de fomento CNPq/SAE.

\footnotetext{
1 - AZEVEDO, M.F. \& ANGRISANI, R.G. Desenvolvimento das Habilidades Auditivas. Tratado de Audiologia. Cap 48, p373-379, 2015.

2 - COLELLA-SANTOS, M.F. \& LIMA, M.C.M.P., Monitoramento do Desenvolvimento da Audição e Linguagem em Lactentes com Indicador de Risco para Perda Auditiva. Tratado das Especialidades em Fonoaudiologia. Cap.113 p.874-877, 2014.

3 - JOINT COMMITTEE ON INFANT HEARING (US JCIH). Year, 2007 Position Statement: principles and guidelines for early hearing detection and intervention programs. Pediatrics. 120; 898-921, 2007.

4 - LEWIS, D.R. et al, Comitê Multiprofissional em saúde auditiva COMUSA. Braz J Otorhinolaryngol. 2010; 76(1) p.121-128.

5 - RIBEIRO, F.M. Indicadores de Risco para a Deficiência Auditiva no Contexto Atual da TANU. Tratado de Audiologia. Cap 49, p381-385, 2015.
} 